\title{
Investigation of Pipe Separation Technology in the Oilfield
}

\author{
Xingfu Zhong ${ }^{1, a}$ Yingxiang $\mathrm{Wu}^{1}$ Songmei $\mathrm{Li}^{2, \mathrm{~b}}$ Pengju $\mathrm{Wei}^{2}$ \\ ${ }^{1}$ Institute of mechanics, Chinese academy of sciences, No.15 Beisihuanxi Road, Beijing, 100190 \\ ${ }^{2}$ Engineering \& Research Center of Field Construction, Engineer Corp. CNOOC, Tianjin, 300452 \\ axfzhong@imech.ac.cn, ${ }^{\mathrm{b}}$ lism@cnooc.com.cn
}

Keywords: Oil-water-gas, pipe separation, separator

\begin{abstract}
Crude oil separating is an important technological process in the petroleum industry. Pipe separation technology (PST) is a new kind of separating method in oil-water-gas separation. To compare with conventional gravity separators, the new separator based on PST is low weight, low cost, efficient and convenient to maintain. This paper introduces this new compact separator, technological process and performance test. The test results show that the compact separator has good separating effect. When the water-cut inlet is from $50 \%$ to $60 \%$, and the mixture flow rate is from 40 $\mathrm{t} / \mathrm{hr}$ to $100 \mathrm{t} / \mathrm{hr}$, the water-cut in oil outlet is less than $5 \%$, and the oil-cut in water is less than $100 \mathrm{mg} / \mathrm{l}$.
\end{abstract}

\section{Introduction}

Pipe separation technology (PST) is a new kind of separating method in oil-water-gas separation. In the last few years, pipe separator has become a new generation of centrifugal oil-water separator, and has been successfully used in waste water treatment. Pipe separator is simple structure, small size, light weight and low operating cost.

Institute of mechanics, Chinese academy of sciences, have researched PST from 1999. The research on the PST includes theoretical, experimental, setting up multiphase loop facility and separating device [1]. They developed a combined separator based on the principles of gravity, centrifugation and expansion. The combined separator is high efficiency and quick separation [2]. Some theoretical and experimental research for the oil-water separation in the helical pipe is developed [3, 4].

A new combined high efficiency compact separator of oil-gas-water is designed and made in 1/10 scale since 2001. The separator which utilized the principles of gravity, expansion and centrifugation is designed into a novel structure. Its key components are helical pipes, T-shaped pipes etc [5, 6]. The bulk and weight of this new separator is less $30 \%$ than the conventional separator of the same handling capacity. Since 2005, the applications of multi-bifurcated pipes in separating gas-liquid and liquid-liquid two phase flows have been investigated [6]. The numerical and experimental study on cylindrical hydro-cyclone in oil-water separation was developed $[7,8]$. The results can be used to optimize the structure of cylindrical cyclones and provide some guidance for the use of PST. This paper introduces the PST. It includes technological process, performance test, and result analysis.

\section{Working principle}

\section{a) Gas-liquid separation}

The cyclone is used to separate gas and liquid. The separation is achieved on centrifugation and gravity effects. It is a conventional gas-liquid separation method.

\section{b) Separation in T-shaped pipes}

The separation in T-shaped pipes is achieved only on gravity effect. It is used to separate oil and water or gas and liquid at low velocity and large density difference. The rising of oil droplets in the T-shaped pipe is governed by Stokes's Law. This function, simply stated is shown in the following equation: 


$$
\mathrm{V}_{\mathrm{p}}=\frac{g}{18}\left(D_{p}-\mathrm{D}_{\mathrm{c}}\right) \frac{d^{2}}{\mu}
$$

Where: $\mathrm{V}_{\mathrm{p}}=$ droplet settling velocity, $\mathrm{m} / \mathrm{s}$

$\mathrm{g}=$ gravitational constant, $9.80 \mathrm{~m} / \mathrm{s}^{2}$

$\mathrm{D}_{\mathrm{p}}=$ density of particle (droplet), $\mathrm{kg} / \mathrm{m}^{3}$

$\mathrm{D}_{\mathrm{c}}=$ density of continuous fluid, $\mathrm{kg} / \mathrm{m}^{3}$

$\mathrm{d}=$ diameter of particle, $\mathrm{m}$

$\mu=$ absolute viscosity of continuous fluid (water), $\mathrm{cp}$

\section{c) Cylindrical hydro-cyclones}

This separation is achieved on centrifugal effect. Oil and water enter the vertical separator section through the reducing area nozzle which increases flow velocity. The swirling motion in the cylindrical pipe produces a centrifugal separation, an oil-rich stream exits through the top overflow and a water-rich stream leaves the system through the bottom underflow. The separating velocity of oil droplets in a pipe is governed by force of centrifugation. It stated is shown in the following equation:

$$
\mathrm{F}_{\mathrm{c}}=\frac{\pi}{6} \mathrm{~d}_{\mathrm{p}}^{3} D_{p} \frac{u_{t}^{2}}{r}
$$

Where: $F_{c}=$ force of centrifugation, $N$

$\mathrm{d}_{\mathrm{p}}=$ diameter of particle (droplet), $\mathrm{m}$

$\mathrm{D}_{\mathrm{p}}=$ density of particle (droplet), $\mathrm{kg} / \mathrm{m}^{3}$

$\mathrm{u}_{\mathrm{t}}=$ tangential velocity of continuous fluid (water), $\mathrm{m} / \mathrm{s}$

$\mathrm{r}=$ distance between of particle and axis pipe, $\mathrm{m}$

\section{Design parameters of new type separator}

The new separator consists of pipe system and tank system. The tank has two functions. One function is to buffer, the other is to separate again. It is $12 \mathrm{~m}$ long and $2.4 \mathrm{~m}$ diameter. The design parameters are:

a. Gas flow rate is $17000-20000 \mathrm{~m}^{3} / \mathrm{d}$

b. Liquid (oil and water) flow rate is $3700 \mathrm{t} / \mathrm{d}$

c. Liquid concentration in gas outlet is less than $50 \mathrm{mg} / \mathrm{m}^{3}$

d. Oil-cut in water outlet is less than $1000 \mathrm{mg} / \mathrm{l}$

\section{Test objectives}

There are three major objectives of this test. The first is to investigate actual efficiency and handling capacity. The second is to inspect separation effect, especially, oil-cut in water outlet. The third is to evaluate performance of PST. The separation of oil and water was key point this time. The effect of gas separation was not inspected, and not evaluated.

\section{Technological process}

The test fluid is the crude oil which comes from the old production line of Boxi oilfield. Figure 1 is the process flow diagram. The test fluid passes through the new separator first, and then flows into storage tank. Finally, it flows back to the old production line. The new separator consists of separating device of gas and liquid, T-shape pipe and cylindrical hydro-cyclone. The storage tank is divided into three parts. They are water room, mixing room and oil room. The water room stores water-rich stream from T-shape pipes. The mixing room stores the mixture of oil and water. The oil comes from water room and the water comes from cylindrical hydro-cyclone. The oil room stores oil from mixing room and cylindrical hydro-cyclone. The new separator picture in the oilfield is shown in figure 2. 


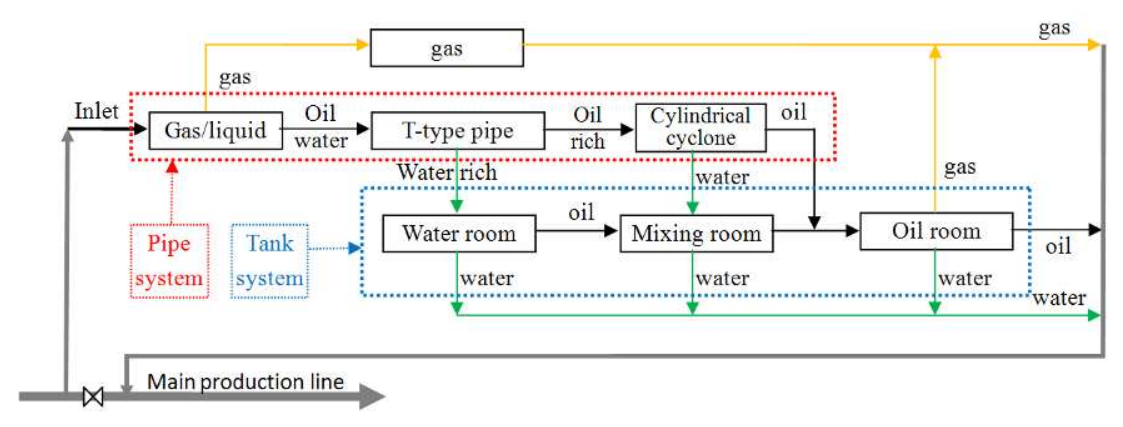

Fig. 1 The process flow diagram of test

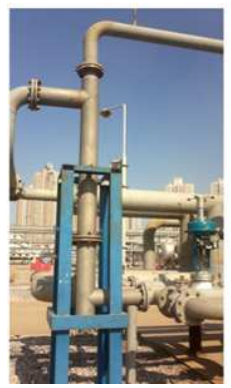

(a)

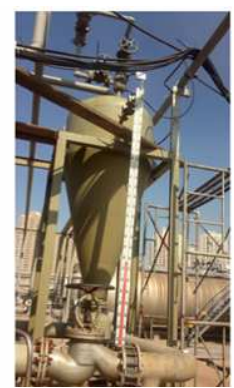

(b)

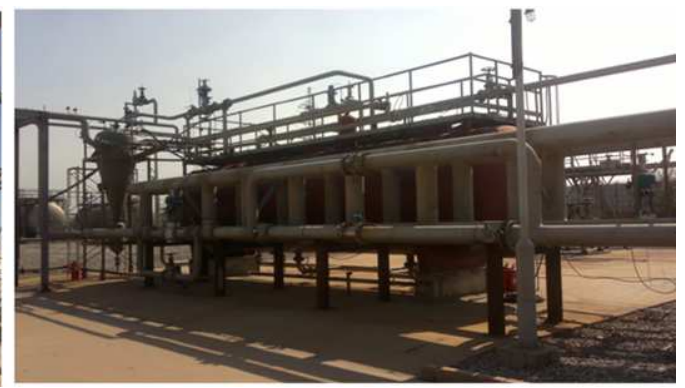

(c)

Fig. 2 The device of the new separator (a) cylindrical hydro-cyclone; (b) device of gas and liquid;

(c)T-shape pipes and storage tank.

\section{Test results and analysis}

The test sample and analysis report were relegated to third party. The third party was responsible for sampling water and oil, and providing analysis result. There were 25 samples in this test. The sampling positions located at old production line, oil and water outlets at the old separator and new separators. Table 1 shows the results of field test. By the way, the inlet pressure is $0.68 \mathrm{MPa}$. The inlet temperature is $65^{\circ} \mathrm{C}$. The mixture flow rate is from 40 to $100 \mathrm{t} / \mathrm{hr}$. The inlet water-cut is from 51.8 to $64.2 \%$.

Table 1 The results of field test

\begin{tabular}{|c|c|c|c|c|c|c|}
\hline Item & Qi,t/hr & Ki, $\%$ & Kwater old, $\%$ & Kwater new,\% & Koil old,mg/l & Koil new,mg/l \\
\hline $\mathbf{1}$ & $\mathbf{4 0}$ & $\mathbf{5 1 . 8}$ & $\mathbf{1 8}$ & $\mathbf{2 . 8}$ & $\mathbf{4 8 6}$ & $\mathbf{2 6 . 4}$ \\
\hline $\mathbf{2}$ & $\mathbf{5 0}$ & $\mathbf{6 0 . 6}$ & $\mathbf{2 0}$ & $\mathbf{3 . 2}$ & $\mathbf{5 7 8 . 2}$ & $\mathbf{7 6}$ \\
\hline $\mathbf{3}$ & $\mathbf{7 0}$ & $\mathbf{6 4 . 2}$ & $\mathbf{2 5}$ & $\mathbf{4 . 8}$ & $\mathbf{5 4 2 . 3}$ & $\mathbf{6 8}$ \\
\hline 4 & $\mathbf{8 0}$ & $\mathbf{5 8 . 6}$ & $\mathbf{2 4}$ & $\mathbf{4 . 7}$ & $\mathbf{5 2 6 . 8}$ & $\mathbf{5 4}$ \\
\hline $\mathbf{5}$ & $\mathbf{1 0 0}$ & $\mathbf{5 4 . 7}$ & $\mathbf{2 1 . 1}$ & $\mathbf{4 . 1}$ & $\mathbf{5 0 6 . 6}$ & $\mathbf{3 6 . 6}$ \\
\hline Average & $\mathbf{6 8}$ & $\mathbf{5 7 . 9}$ & $\mathbf{2 1 . 6}$ & $\mathbf{3 . 9}$ & $\mathbf{5 2 7 . 9}$ & $\mathbf{5 2 . 2}$ \\
\hline
\end{tabular}

Where $\mathrm{Qi}=$ inlet mixture flow rate, $\mathrm{t} / \mathrm{hr}$

$\mathrm{Ki}=$ inlet water-cut, $\%$

Kwater old $=$ water-cut in oil outlet in the old separator, $\%$

Kwater new $=$ water-cut in oil outlet in new separator, \%

Koil old $=$ oil-cut in water outlet in the old separator, $\mathrm{mg} / \mathrm{l}$

Koil new $=$ oil-cut in water outlet in new separator, $\mathrm{mg} / \mathrm{l}$

\section{a) Water-cut in oil outlet}

From analysis report, the results of the old and new separators are compared. In the old separator, the maximum of water-cut in oil outlet is $25 \%$, the minimum is $18 \%$, and the mean value is $21.6 \%$. But in the new separator, the maximum of water-cut in oil outlet is $4.8 \%$, the minimum is $2.8 \%$, and the 
mean value is $3.9 \%$. The water-cut in oil outlet of new separator is cut down $81.9 \%$. Figure 3 shows the comparison of the water-cut in oil outlet between two separators. (a) is the water-cut in oil outlet along with inlet mixture flow rate. (b) is the water-cut in oil outlet along with inlet water-cut.

\section{b) Oil-cut in water outlet}

In the same way, the oil-cut in water outlet is from 486 to $578.2 \mathrm{mg} / 1$ in the old separator. It is from 26.4 to $76 \mathrm{mg} / \mathrm{l}$ in the new separator. It is cut down $90.1 \%$ in the new one. Figure 4 shows that the comparison of oil-cut in water outlet between two separators. (a) is the oil-cut in water outlet along with inlet mixture flow rate. (b) is the oil-cut in water outlet along with inlet water-cut.

Because of the actual production situation, the maximum of liquid flowrate was only $100 \mathrm{t} / \mathrm{hr}$ rather than $3700 \mathrm{t} / \mathrm{d}(=154.2 \mathrm{t} / \mathrm{hr})$. But the analysis results showed that design parameters were up to grade. Although the flowrate was not be maximum, the indication correspond with design parameters.

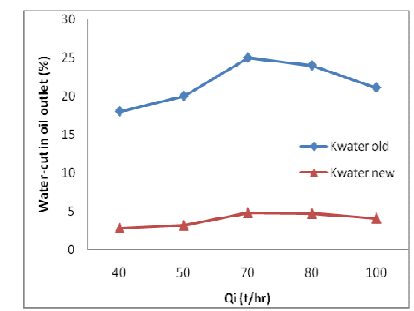

(a)

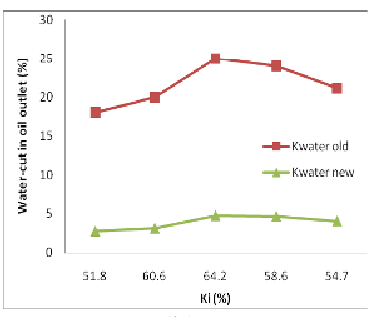

(b)

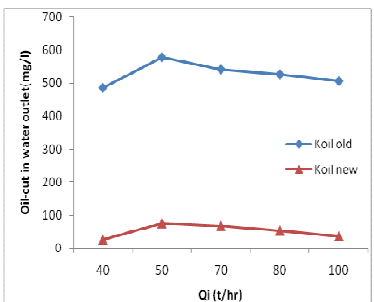

(a)

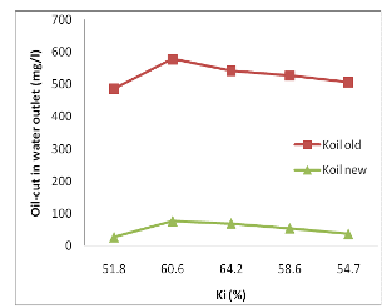

(b)

Fig. 3 The comparison of water-cut in oil outlet between two separators (a) The water-cut in oil outlet along with mixture inlet flow rate; (b) The water-cut in oil outlet along with inlet water-cut.

Fig. 4 The comparison between oil-cut in water outlet between two separators (a) The oil-cut in water outlet along with inlet mixture flow rate; (b) The oil-cut in water outlet along with inlet water-cut.

\section{Conclusions}

The performance test shows that PST is a good method to separate mixture of oil water and gas. The water-cut in oil outlet is less than 5\%, and the oil-cut in water outlet is less than $100 \mathrm{ppm}$. They are within the ranges of test parameters. The new compact separator was designed by PST has good separating effect in the oil-water separation. The test results illustrate that the pipeline separator based on PST is going to have a good prospect. Pipeline separator is simple structure, small size, light weight, and low operating costs. It will bring revolutionary change in oil-water-gas separation.

\section{References}

[1] Zhichu Zheng, Yingxiang Wu. China Offshore Oil and Gas.1999, Vol.11(1),p.24

[2] Zhou yong, Yingxiang Wu, et al. Hydrodynamics. 2004,Vol.19(4),p.540

[3] Daotong Gong, Yingxiang Wu, et al. Hydrodynamics. Ser.A, 2004,Vol.19(4),p.540

[4] Zhichu Zheng, Jun Guo, et al. The $18^{\text {th }}$ forum of hydrodynamics. Ocean Publishers (2004)

[5] Zhichu Zheng, Yong Zhou, et al. Experiments and Measure in Fluid Mechanics. 2005,Vol.19(1),p94

[6] Liyang Wang, Yingxiang Wu, et al. Shipbuilding of China. 2009,Vol.50(A11),p380

[7] Haifei Liu, Xingfu Zhong, et al. Shipbuilding of China. 2009,50 (A11),p.369

[8] Shiying Shi, Yingxiang Wu, et al. Shipbuilding of China. 2009,50 (A11),p.362 
Sustainable Development of Natural Resources

10.4028/www.scientific.net/AMR.616-618

Investigation of Pipe Separation Technology in the Oilfield

10.4028/www.scientific.net/AMR.616-618.833 